\title{
Study on the Factors Influencing the Deep Learning Behaviors under the Information-based Teaching Environment for Vocational English Oral Language Courses
}

\author{
Zhaoxi Wei \\ Beijing Information Technology College \\ Beijing, China 100018
}

\begin{abstract}
The research has been carried out in order to explore the influences of the information-based teaching environment on the changes of English learning behaviors in the higher vocational education. It is found out in the researches that factors influencing the deep learning behaviors under the information-based teaching environment for vocational English oral language courses respectively are: construction of classroom atmosphere for foreign language, application of the "relevance" principle of the student expectation and value, adoption of the teaching methods under the concept of "connection", adoption of the deep learning strategies of "learning in units and using as a whole", influence of the thinking models on the deep learning and the orientation of pertinent feedbacks etc.
\end{abstract}

Keywords-vocational English; deep learning behaviors; influencing factors

\section{INTRODUCTION}

In recent years, it has become the ultimate goal and prospect of English teaching in higher vocational education under the information-based teaching environment to enrich the teaching means of foreign language course through the modern education technology and network resources, guide students to get the best learning effects in the classroom teaching and stimulate them to study independently after class, finally improving students' language practice ability. However, do the English teaching effects of higher vocational education under the information-based teaching environment improve? Do the learning behaviors and abilities change under the information-based teaching environment? Therefore, the research on the in-depth learning behaviors in the oral English course of higher vocational education under the informationbased teaching environment is conducted.

\section{RESEARCH ON THE CURRENT SITUATION OF DEEP LEARNING UNDER THE INFORMATION-BASED TEACHING ENVIRONMENT FOR VOCATIONAL ENGLISH ORAL LANGUAGE COURSES}

Recently, using the modern educational technologies and the network resources to enrich the teaching methods of foreign language, guiding the students to maximize the learning effects in the classroom teaching, inspiring students to play the autonomous learning ability after class and finally realizing the comprehensive promotion of language practice ability of students have become the ultimate aims and prospects of the vocational English teaching under the information-based teaching environment. Therefore, to comprehensively and meticulously understand the development of deep learning behaviors under the information-based teaching environment, the research group respectively conducts questionnaire surveys in three aspects of the self-knowledge of the current situation of vocational English oral language learning, class practice of vocational English teaching and the deep learning demands of the vocational English oral language with the assistance of informatization. Details are as follows:

\section{A. Investigation of the Learning Status of the Vocational English Oral Courses under the Informatization}

The results show that: the students possess the relatively clear and positive cognition of the learning of vocational English oral courses; possess certain planning in the learning of vocational English oral courses; but possess insufficient initiative which desiderates the effective guidance of teachers. In the self-knowledge and evaluations of students toward the learning of vocational English oral courses, the results for the satisfaction and dissatisfaction are similar which respectively are $50.06 \%$ and $49.94 \%$. At the same time, in the cognition of "the key to well learning oral English", the factor of "self" accounts for $39.68 \%$; the interest follows accounting for $32.6 \%$. It is thus clear that the students have relatively correct and clear cognition of learning status of oral English of themselves which will further exert influence on whether they can precisely design the personalized oral English learning plans or objectives for themselves in the future or after class.

\section{B. Course Practice Status and Effects Investigation of the Vocational Oral English under the Assistance of Informatization.}

1) The overall satisfaction of vocational English oral teaching is $92 \%$ basically holding the line with the satisfaction investigation of various subitems which shows the 
effectiveness of this investigation. In the investigation of coconstruction of classroom atmosphere of students and teachers, classes with the "relaxing and pleasant" and "quiet and comfortable" atmospheres account for $89 \%$. This harmonious and relaxing classroom atmosphere is good for reducing the anxiety of students on the learning of vocational oral English which can improve the teaching effects to certain extent.

2) The investigation on class activities of vocational oral English shows that the activities which can improve the oral expression ability, cooperative ability and critical thinking skills such as group activities and topic discussion etc are the most popular among students and can excite their strong interests of the class; secondly, the autonomic learning activities also ascends in top three which means that under the online education environment, the demands of students on information and on personal learning space are stronger than that of traditional teaching environment with "blackboards and chalks". At the same time, the teachers should "leave spaces" in the class teaching and provide more time or space for students for thinking, introspection and autonomic learning which is good for the understanding and expansion of class teaching contents of students and further is good to cultivate their reflective abilities and deep learning abilities.

3) Influence of information-based teaching method on the vocational oral English teaching. The results show that this method motivates the learning ability $(33.7 \%)$, presents the diversified learning resources $(45.42 \%$, grants students with another form to participate in the activities (46.89\%) and builds the stereoscopic teaching space which is also good for the cultivation of learning ability with autonomy and consciousness of students. To this end, what the students want to realize the most are the answering at any time $(49.82 \%)$ and the repetitive reflection of knowledge point $(49.82 \%)$ as well as the one-to-one assisted learning (33.58) and the formation of learning community (33.58\%) which fully manifest the new features with individualization and pertinence of vocational English learning under the information-based teaching environment and the teamwork under construction of learning community.

\section{Investigation on the Demands of Students for the Vocational Oral English Teaching under the Assistance of Informatization.}

1) The gradual change on the roles of vocational English teachers under the information-based environment. The knowledge transmitters account for $68.38 \%$. Although currently, in the era with knowledge explosion and the era where the fragmented and miniaturized knowledge are gradually sizing the network headline, the requirements of comprehensiveness, systematization and omniscience are too rigorous and can't be accomplished, the era also puts forward higher requirements for the teachers. The second is the instructor of learning activities (58.24\%) and the demand analyst $(46.15 \%)$ which is also the expectations of students for the roles of vocational English teachers under the information technology environment. Understand students, care for

Fund Support: Research Project of Education and Teaching Reforms for Colleges and Universities in Beijing in 2015 (2015-ms217) and Phased Objectives of College Project of Beijing Information Technology College (XY-YN-06-201618) students, cultivate the acuity for student demands and further help students to formulate the learning plans and objectives conforming to their demands which will encourage students to give play to their maximal learning initiative and realize the true deep learning.

2) Teaching methods with the assistance of informatization. The autonomic learning activities and practices of APP type are more popular among students $(51.16 \%)$. The topic discussion $(47.74 \%)$ and the group activities (45.79\%) and other activities of same type are good for the improvement of oral expression ability, cooperative ability and critical thinking skills. To this end, the teachers can appropriately adopt those activities according to the teaching objectives and requirements which is beneficial to activate the class atmosphere and motivate the learning motivation of students.

3) During the realization of expected objectives and values of information-based courses, what the students want to realize the most is to improve the fundamental English listening and speaking skills $(65.45 \%)$, learn the contents related to the future work $(56.29 \%)$ and the contents related to the selfcultivation and social etiquettes $(42.61 \%)$. Further, the students are more concerned with the improvement and cultivation of their English communication ability $(80.22 \%)$ and the obtaining of language knowledge for the appropriate expression in workplace $(56.9 \%)$ and the identification in workplace on the cooperation and communication abilities $(48.96 \%)$. To this end, the integration of informatization and course teaching contents can emphasis on the cultivation of abilities in workplace with listening and speaking first, reading and writing following to provide the language knowledge and further support the listening and speaking.

\section{STUDY ON THE FACTORS INFLUENCING THE DEEP}

LEARNING BEHAVIORS UNDER THE INFORMATION-BASED TEACHING ENVIRONMENT FOR VOCATIONAL ENGLISH ORAL

\section{LANGUAGE COURSES}

It is found out in the investigation that in the academies launching or using the information-based teaching methods to assist the vocational oral English teaching, the students are relatively satisfactory to the vocational oral English teaching status with the assistance of informatization which on one hand benefits from using the information technology to conduct overall design of course learning, convergence of teaching links, development of classroom activities, on-line practice after class, on-line quiz investigation and other abundant and changeful forms to bring the teachers with the unexpected interaction effects; on the other hand, benefits from the active application and extensive promotion of information-based teaching methods in the classroom teaching under the time background of "Internet plus" which makes the class more lively and gets the invisible class skipping students back and improve the students' participation. We can say that the information-based teaching environment provides with teaching methods beneficial to the changeful and abundant course teaching and builds the favorable platform for the realization of deep learning of vocational oral English courses. However, when reviewing from the investigation results, there are still various teaching behaviors under the Network environment influencing the deep learning effects of 
vocational oral English or the satisfaction on course learning such as: the construction of harmonious and relaxing English classroom atmosphere under the network environment; implementation of "relevance" principle for motivating the student motivation and improving the student expectation and value under network environment; adoption of diversified teaching methods under the "connection" concept; application of the course deep learning strategies by "learning in units and using as a whole" under the network environment; influence of the thinking models on the deep learning and the orientation of pertinent feedbacks under the network environment etc. Details are as follows:

\section{A. The Construction of Harmonious and Relaxing English Classroom Atmosphere under the Network Environment}

The students need the delicate emotion balance for the smooth study. The powerless emotions (boredom, indifference and detachment) are not the ideal emotions. Energetic, relaxing and sensitive thirst for knowledge is the ideal learning status. The students need to study actively and readily with no threats and pressure. The teachers should create the sense of security through helping students get rid of the state with low learning efficiency and clearing the activity objectives to further promote the students in the actively motivated emotion state. In this way, they will focus on study and devote themselves in their study. At the same time, the trust and support between teachers and students will promote the students who really care about study to keep learning and exploring.

\section{B. Implementation of "Relevance" Principle for Motivating the Student Motivation and Improving the Student Expectation and Value under Network Environment}

In the learning conditions, the motivation will influence the orientation, intensity, persistence and quality of the learning activities that students are engaged in. At the same time, if the students think the objectives they are pursuing have value and have active expectation on success, they will have higher motivation to keep on the deep learning. Therefore, to motivate the deep learning behaviors on courses, a series of relevance principles shall be implemented: not only clearly inform the relevance between the skills learnt by students and the future career, but also design the suitable study materials for the close relevance with the student interests as well as design the learning tasks under real contexts and point out that the students must pay attention to the learning activities and provide the targeted feedback for the close relevance among value and expectation of learning and the personal interests, current academic, future career and class activities so as to provide for students with infinite opportunities and possibilities for self-motivation and self-reflection.

\section{Adoption of Diversified Teaching Methods under the "Connection" Concept}

The learning under the era of Internet plus is the process to form the network connecting various knowledge points and the process to build the connection between the new knowledge of the original background knowledge or initial knowledge of the students and form the connection of new and old knowledge in the expression forms of language, words, symbols and data etc so as to be convenient for the further processing. Only in this way can the students accumulate necessary supporting knowledge before the deep learning. For this, the teachers need to adopt diversified teaching strategies and methods, such as the methods of stories, charts, analogy or metaphor to explore various possible approaches for students to obtain information and cultivate the students to independently construct the "meaningful" knowledge organization forms and accomplish the construction of learning organization modes from connection to construction and from forms to meaning so as to be favorable for the realization of course deep learning objectives.

\section{Application of the Course Deep Learning Strategies by "Learning in Units and Using as A Whole" under the Network Environment}

The biggest influence of network era on learning is that the tendency of fragmented knowledge, fragmented time and fragmented learning is becoming more and more serious. For the process of course deep learning, those fragments are the damage and threat to learning system, but are also the opportunity to facilitate the formation of personal learning cognition of students; the kind of reconstitution to connect with the individual original knowledge system based on the integration of fragmented knowledge of students and to further reach to the deep learning phase through understanding and processing. They can conduct the individual creative integration to the knowledge system of courses after the fragmentization to further realize the deep learning effects and highlight the cognition process for the construction of personal meanings under the course framework.

\section{E. Influence of the Thinking Models on the Deep Learning under the Network Environment}

The learning under the network era is facing challenges of fragmentization and large overload volume of information. There are full of contradiction, conflicts, cross, fuzziness and other complicated relations between information and fragmented knowledge exerting great impact and obsession on the seizing of course system and the course deep learning. Therefore, the thinking models which can integrate the information with fragmented knowledge are desiderated. From the critical thinking to parallel thinking to the currently advocated "inclusive thinking", all of those thinking models demonstrate the opinions, faiths and attitudes towards matters in different forms and focuses. They also provide the materials mastered by students and processed through different perspectives and add the understanding of the individuals on the meanings in the integration of material forms which promotes the cultivation of course deep learning abilities of students.

\section{F. The Orientation Role of Pertinent Feedbacks in the Course Deep Learning under the Network Environment}

For the promotion of deep learning of students, only focusing on the learning gains obtained by students is far from enough. Only combining with the effective feedback and clearing the current knowledge and behavioral expression level can guide the students to keep working hard towards the 
established learning objectives. The oral English teaching under network environment has possessed the abundant learning resources, various teaching supplementary means and various practice or activity forms and the limitless input or intake of information has made the output or produced learning effects of students appear to be especially important. Providing with the targeted effective feedback timely will be crucial to the deepening of course learning effects. To this end, focus on the importance sequences of course teaching feedback and focus on the targeted feedback of specific objective; balance the advantages and disadvantages in the feedback to further promote the efficiency of students and strengthen the learning motivation; establishing the regular feedback opportunities and promoting the students to keep improving their understandings are favorable to the implementation of deep learning strategies; at the same time, establish the relevance among homework, activities, examinations and feedback and form the complete learning cycle of students under the course deep learning to further play the maximum values of feedback.

\section{CONCLUSION}

We have known from the above research and discussion that the information-based teaching environment just provides the favorable conditions for the promotion of deep learning. Only fully emphasizing on the construction of learning environment, the motivating of learning motivation, formation of learning community, "learning in units and using as whole" of knowledge after balancing the cognitive loads and the construction of reasonable and scientific evaluation system in the classroom teaching and course teaching can the smooth transition from external learning to deep learning of students be realized and can the occurrence of deep learning behaviors under the information-based environment of students be realized.

\section{REFERENCES}

[1] Wang Zhuli, Fragment and Reconstitution [M]. Beijing, Publishing House of Electronics Industry, 2016

[2] Zhaoxi Wei, Gang Ji. Discussion on Effective Optimization of Foreign Language Teaching Interaction under Network Environment [J]. ICADCE 2016, Atlantis Press, 2016(05) 